\title{
新型冠状病毒疫情下《流体力学》线上课程的教与学
}

\author{
焦朋朋 ${ }^{1}$ 王满堂 ${ }^{1}$ 郭双祯 ${ }^{2}$ \\ 1 本庄学院 城市与建筑工程学院 2 齐鲁工业大学 环境科学与工程学院 \\ DOI:10.32629/er.v3i4.2599
}

\begin{abstract}
[摘 要] 在当前疫情形势下, 实施线下教学已经成为一种奢望,为了保障学生 “停课不停学”, 组织开展《流体力学》课程的线上教学,线上教学 过程中,从学生的需求与课程特点出发, 不断丰富学生线下预习阶段、教师线上教学阶段、学生线下复习阶段、教师远程辅导阶段的各类教学资 源, 并通多种教学手段相互配合, 顺利实施了线上教学。《流体力学》线上教学过程中利用疫情期间的事例, 对学生进行思政教育, 帮助学生调整心 态, 消除恐梳心理。通过言传身教, 替移默化地影响学生, 使学生更加热爱生活、热爱祖国。
\end{abstract}

[关键词] 线上教学; 土木工程; 流体力学

2020年的春季学期注定是一个不平凡的学期, 新型冠状病毒肺炎疫情 (简称疫情) 扰动着全国人民的心。为了此次疫情防控, 保证广大师生的生 命安全, 教育部门做出了推迟开学的决定。与此同时, 教育部办公厅、工业 和信息化部办公厅联合印发关于 “停课不停学” 有关工作安排的通知, 各 地各类学校纷纷采取线上教学方式, 贯彻落实 “停课不停学” 要求 ${ }^{[1]}$ 。例 如奉庄学院组织全校教师参加线上教学培训, 并利用雨课堂、中国大学 MOOC、智慧树、腾讯课堂、钉钉直播等多种平台与技术手段开展线上教学。 《流体力学》作为土木工程的一门基础课程也在统计范围内。《流体力学》 课程具有概念抽象、公式繁多、叙述晦涩、求解困难等特点 ${ }^{[23]}$ 。学生在 学习过程中普遍反映难度大, 被学生戏称为 “天书”。在线下教学过程中常 常需要借助PPT演示与书写板书为学生推演流体静力学微分方程与流体动 力学微分方程等, 学生需要 “坚起耳朵, 琤大眼, 动起脑子、伸出手” 才能 掌握相关知识点内容。而在当前疫情形势下, 线下教学成为奢望难以开展。 对于《流体力学》这门理论性强、难度大的课程, 由于在线教学硬件条件 的限制, 难以实施线下教学采用的 “望闻问切” 教学方法, 无法实时把握学 生的思想与学习动态。在此条件下如何保证线上教学质量与学习效果, 课 程实验如何开展, 值得探讨与思考。

\section{1 《流体力学》课程知识点统计分析}

《流体力学》是土木工程专业的基础核心课程之一 ${ }^{[4]}$ 。该课程的主要 任务是使学生掌握水流运动的基本概念, 基本理论、基本计算方法和一定 的数值计算及实验技能, 培养学生能够较好地分析和解决土木工程专业 中涉及流体力学问题的能力, 为后续学习专业课程、从事专业技术工作 或进行科学研究打下坚实的基础。根据《高等学校土木工程本科指导性 专业规范》的要求, 流体力学主要涉及流体静力学、流体动力学、流动 阻力、有压流动、明渠流动、堰流和渗流及波浪理论基础等七大部分的 知识内容, 共有 29 个知识点需要土木专业本科学生学习, 其中流体的主 要物理性质、重力场中液体静压强的分布、作用在面上的总压力等 18 个 知识点需要掌握, 作用在流体上力、层流运动等 10 个知识点需要熟悉, 剩 余为需要了解的知识点, 核心学时为 32 个学时 ${ }^{[5]}$ 。对于水力学实验要求 的知识技能点共有 2 个, 其中需要掌握的有 2 个, 即管流平均流速, 总水头 的测定, 测压管水头, 流体管流运动的能量相互转换关系验证; 层流、紊 流的水头损失与断面平均流速的关系测定, 层流、紊流现象观察, 雷诺数 的计算。从对知识点与知识技能点的要求上不难看出《流体力学》课程 在土木工程专业的重要性。

\section{2 《流体力学》线上教学的优势与不足 \\ 2.1 《流体力学》线上教学的优势 \\ 2.1.1打破了地域性和时间的局限性}

传统的线下教学, 只有在特定的时间与特定的地点才能开展教学。线 下教学时长固定偪化, 无论学生是否愿意听, 是否能够保持充足的精力完 成听讲, 都必须在教室听教师讲授内容, 可能会在一定程度上造成学生的 逆反心理, 从而在心理上排斥甚至厌恶《流体力学》 ${ }^{[6]}$ 。然而线上教学恰 恰能规避此问题, 学生可以根据自己的时间和心情去选择听课的时间与方 式, 可以随时暂停或重复播放并思考讲授的内容。

2.1.2线上课程教学资源丰富

线下教学受授课学时的限制, 教师难以有足够的时间去补充课本之外 的内容, 特别是最新的科学前沿难以引入课堂。然而通过线上教学方式可 以将课本以外的内容或前沿研究引入到线上课堂中, 学生根据自己的兴趣 进行选择性学习。此外, 对于重点难点内容, 可以跟随名校名师开设的《流 体力学》线上课程进行学习, 感受名师的风采, 提升学生学习《流体力学》 的兴趣。

\subsection{3线上课程匿名交流更加顺畅}

当代的大学生都非常在乎自己的形象, 特别是学习方面, 好多学生都 是碍于面子, 不想表露自己对某些内容没听懂不理解的事实, 更不想因 无法正确回答教师的提问而受到同学的嘲笑或讽刺。线上课程匿名交流 就从根本上避免了此问题, 匿名状态下, 学生非常乐意参与线上的沟通 与交流, 有不明白的地方会主动向教师发出提问, 这在线下教学过程中 是非常少见的。

2.2 《流体力学》线上教学的不足

2.2.1无法直面学生, 难以实时掌握学生的学习动态

线上教学无法面对面与学生交流, 无法通过 “望闻问切” 的方法实时 掌握学生的学习状态。线下教学过程中学生如果能够听明白或者理解某个 知识点时, 会在学生的表情中或者肢体动作中有所反馈, 当然听不懂时也 会有对应的微表情或者肢体动作, 通过观察就能及时准确的把握学生的掌 握情况。而在线上授课过程中, 难以做到这一点, 甚至无法把控学生是否在 认真听讲。

\subsection{2网络信号不稳定影响授课效果}

线上直播授课最严重的问题就是网络信号的问题, 一旦出现信号中断 或者卡顿, 都会影响学生学习或者教师讲授的心情, 从而使得授课效果大 打折扣。特别是对于一些地处偏远地区的学生来讲, 网络信号时常会出现 问题, 从而导致学生学习受到影响。

\subsection{3学生自控力不足, 仅形式上参与线上学习}

部分学生在进入大学后过于放松自己, 沉迷于网络游戏, 自己无法掌 控自己, 在当前疫情形势下无法回校上课, 线上授课过程中教师无法时刻 查看学生的在线学习状态, 导致少部分自控力差的学生, 仅形式上参与线 
上学习, 而实际可能还在游戏的世界或者梦乡里驰骋。本学期《流体力学》 课程安排在每周二上午 $8: 00-10: 00$ 在线直播授课, 曾做过调查, 真正能够 做到认认真真看直播授课的学生在 $86 \%$ 左右, 而剩余的部分可能属于形式 上参与线上学习的情形。

\section{3 疫情下《流体力学》线上教学的四个阶段}

教学资源是教学的 “三要素”之一, 是学生开展学习活动的基础。针 对《流体力学》的课程特点, 结合学生的学情, 在疫情条件下, 整合《流体 力学》线上教学资源是线上教学活动开展前重要的准备。在教育部与工信 部发出 “停课不停学” 的号召后, 课程教学团队积极行动起来, 充分借助中 国大学 $\mathrm{MOOC}$ 平台的课程资源, 集众家之所长, 收集了哈尔滨工业大学、南京 大学、上海交通大学、西安交通大学等多所著名高校的《流体力学》线上 教学资源, 整合吸收后为学生准备了新学期《流体力学》线上课程 (钉钉直 播）。疫情下 《流体力学》线上教学分解为四个阶段, 即学生线下预习阶段、 教师线上教学阶段、学生线下复习阶段、教师远程辅导阶段。在每个阶段 都为学生准备了充足的学习资源。以动量方程知识点的教学过程为例, 介 绍《流体力学》线上教学过程。

3. 1 学生线下预习阶段

学生线下预习阶段为学生提供了预习PPT、重点难点内容、需要思考 的问题及名校名师讲解动量方程的视频资料, 通过学生提前预习了解动量 方程的相关内容, 并找出自己存在疑惑的地方。

\section{2 教师线上教学阶段}

通过水刀切割机切割金属器件的视频引入, 向学生抛出问题: 为什么 水能够切割金属器物。引导学生思考, 并回忆动量定理, 从而逐步引出动量 方程。通过分析特定控制体在微小时间段内的动量变化, 从而推导出动量 定理。强调动量方程中所涉及的力与速度均为矢量, 在应用过程中要把握 受力方向。引入例题, 并讲解, 重点强调利用动量方程解题时解题步骤, 要 分析题目要求与意图, 确认是否是需要利用动量方程的求解, 若需要利用 动量方程求解, 首先就需要确认并绘制控制体, 其次建立坐标系, 再次选择 正方向, 最后在空间坐标系x, y, z三个方向分别列出动量方程, 然后根据题 目已知条件进行求解, 如需要联立伯努利方程或连续性方程的, 联立后进 行求解。在线授课期间多次强调利用伯努利方程求解的过程。线上教学阶 段为了确保学生的听课质量会设置随机提问, 比如要求学生重述利用动量 方程解决问题的步骤等。为了掌握学生的听课效果, 发起关于动量方程你 是否已经理解掌握的投票, 投票题目设置为 “师者, 所以传道受业解惑也。 人非生而知之者, 孰能无惑? 试问, 诸位关于动量方程是否有惑？”，投票 选项: a学生自幼天资聪颖, 先生所讲皆浅显易懂, 已了然于胸; b学生自幼 天性愚针, 先生所讲形同天书, 鸣呼, 哀哉; c学生已尽全力去跟随先生所讲, 大半内容已经了然, 少惑, 线下单独请教先生; $\mathrm{d}$ 垂死病中惊坐起, 动量方程 我恨你。犹抱琵琶半遮面, 这样的方程让我乱。通过这种略带幽默色彩的 投票引导学生反馈关于动量方程的掌握情况。

此外, 在教师线上教学阶段注重引入课程思政。以动量方程为基础向 课外延伸, 向学生介绍制作口罩的原材料: 喷线布的生产过程, 在喷线布生 产阶段就涉及到了动量方程的基本原理, 并在此过程中向学生传递抗疫必 胜的信念, 同时要求学生做好防护, 调整心态, 积极地应对疫情。

3. 3 学生线下复习阶段

学生线下复习阶段要求学生认真阅读教材内容, 并布置3-5道作业题, 同时要求学生绘制相关章节的思维导图, 从而使学生对所学内容的知识脉
络有宏观的了解。同时向学生推荐关于流体力学学习的微信公众号以便于 学生线下复习。

3. 4 教师远程辅导阶段

教师远程辅导阶段会针对个别学生的问题进行针对性的辅导, 例如在 动量方程计算过程中需要联立伯努利方程, 在伯努利方程求解中又涉及到 了相对压强与绝对压强的问题, 有少数同学对此认识不清, 导致在解题过 程中困难重重, 通过向学生讲解相对压强与绝对压强的概念与计算, 使学 生更好地掌握相关知识。此外, 在此阶段教师会主动联系学生特别是身处 疫区的学生, 给予他们更多精神上的关怀与心理方面的疏导, 告诉他们不 要担心, 要相信党和政府在全体人民的参与和配合下一定会取得抗疫的最 终胜利。

\section{4 结语}

受疫情影响, 我校流体力学课程在线上开课。九周的线上教学过程中, 教师们 “不忘初心, 牢记使命”, 始终贯彻 “以学生为中心、以结果为导向” 的教学理念, 从学生的需求与课程特点出发, 不断丰富学生线下预习阶段、 教师线上教学阶段、学生线下复习阶段、教师远程辅导阶段的各类教学资 源, 并通多种教学手段相互配合, 顺利实施了线上教学。实践证明, 现有教 学资源和教学模式能够满足《流体力学》线上教学需要, 大部分学生都能 高质量完成学习任务。《流体力学》线上教学过程中利用疫情期间的事例, 对学生进行思政教育, 帮助学生调整心态, 消除恐慌心理, 积极地应对疫 情。线上教学不仅仅传道受业解惑, 更是要言传身教, 潜移默化地影响学生, 使学生更加热爱生活、热爱祖国, 这样的教育才会更符合现代教育理念。

\section{[参考文献]}

[1]教育部.教育部办公厅工业和信息化部办公厅关于中小学延期开 学期间 “停课不停学” 有关工作安排的通知[S].2020-02-12.

[2]杨闻宇.土木工程专业流体力学课程基本理论及其应用的课堂教 学分析[J].教育教学论坛,2018(51):246-248.

[3]间淑霞.土木工程专业 “流体力学” 教学方法探讨 [ J]. 科教文汇 (中 旬刊),2019(08):73-75.

[4]高学校土木工程学科专业指导委员会编.高等学校土木工程本科 指导性专业规范[M].中国建筑工业出版社出版,2011.

[5]教育部.普通高等学校本科专业类教学质量国家标准[M].高等教育 出版社,2019.

[6]刘起霞.流体力学课程 “厌学”的现状分析与改进措施[C].中国力 学学会. 第十五届北方七省市区力学学术会议论文集. 中国力学学会: 中国 力学学会,2014:402-405.

\section{通讯作者简介:}

焦朋朋(1985--), 男, 汉族, 山东德州人,博士研究生, 讲师, 研究方 向: 水污染治理。

\section{资助项目:}

山东省本科教学改革项目“以区域经济发展为导向的地方应用型 高校新工科人才培养模式改革探索——土木工程专业为例” (编号: 10904201803); 教育部高等学校给排水科学与工程专业指导分委员会 项目 “工科视阈下基于 $O B E$ 理念的给排水科学与工程应用型人才培养 模式探索与实践”(项目编号：GPSJZW2019-37)；本庄学院“本庄学 院土木工程专业群建设经费”(编号：2018ZJUZYJS004)；本庄学院水 质工程教学团队建设经费。 